\title{
Construction of the Financial Market System under the New Consumer Concept
}

\author{
Dan Cui \\ Dalian Vocational \& Technical College, Dalian 116035, China; \\ 1471378931@qq.com
}

Keywords: Financial market, new concept of consumer, marketing.

\begin{abstract}
In order to have a thorough understanding of financial market system and better promote its development, first of all, the marketing key points of new concept consumers are analyzed. Based on this, the current situation of financial market is discussed, and the problems existing in the financial system are explored. In addition, for efficiently solving these problems, some reasonable and feasible suggestions are put forward. The results show that the new concept of consumer brings opportunities for the vigorous development of financial market, and the in-depth implementation of consumption finance will effectively promote the construction of financial market. At last, it can be concluded that accelerating the construction of efficient financial market is necessary and essential, and it is key to change the economic growth method and expand the domestic demand.
\end{abstract}

\section{Introduction}

Finance is the blood for the economic development, and it is also the promotion means of economic development. The promotion effect of finance should not only reflected in the funding support of a series of construction projects, but also reflected in the foothold of stimulating domestic demand. Prime Minister Li Keqiang pointed out that expanding domestic demand is the primary task of structure adjustment, and new consumers are the greatest potential of Chinese domestic demand [1]. Apparently, this domestic demand should be achieved not through "investment leading" model of project construction, but through releasing the consumption potential of citizens, to construct the long-term mechanism of "internal demand pulling" model in China. And in this process, the important finance branch - consumption finance cannot be ignored.

American famous consumer psychologist Lewis and Brig put forward the completely new concept of "new consumer" in the book New Consumer Concept [2]. They believed that the difference between new consumers and old consumers is so great that it has exceeded the general imagination. The old consumers will have obvious behavior difference due to the geological and cultural differences, while the new consumers are slightly affected by these factors. Soon, British marketing expert Susan Belcke proposed the concept of new consumer, whose definition has little difference with that of Lewis and Brig [3]. The emergence of new consumer concept subverts the traditional consumption concept, and the previous consumption is mainly reflected in the consumption of things and utilization of invisible products (such as education) provided in the form of activities. The consumption of the new consumption era transfers from material level to spiritual level. In the era of rich products, people have the desire and condition of asking for emotions and spiritual products. The emergence of new consumer concept produces certain attack of the formation mechanism of market. Time, attention and trust all become the rare resources in the society. They are not spontaneously existing in the market, but rooted in new consumers. Only by grasping the time, attention and trust of new consumers and get their credibility can we truly grasp the market.

In the paper, first of all, the marketing key points of new consumers concept are analyzed. Based on this, the current situation of financial market is discussed, and the problems existing in the financial system are explored. In addition, for efficiently solving these problems, some reasonable and feasible suggestions are put forward. At last, it can be concluded that accelerating the construction of efficient financial market is necessary and essential, and it is key to change the economic growth method and expand the domestic demand. 


\section{Key points of marketing of new consumer}

Any industry cannot ignore the group with large scale and rather strong economic strength and guiding the mainstream values of society. But the emergence of unusual new consumers puts forward great challenge for the enterprise marketing. To capture the heart of the consumers, enterprises are supposed to establish the marketing concept with consumer value orientation, judge their value orientation with heightened awareness, and achieve the successful marketing activities through the innovative value creation and flexible value.

Firstly, it is necessary to define the values with heightened awareness. The value here refers to the values recognized by consumers, namely consumer perceptive value (CPV). It must be proposed by consumers and determined by consumers at last. Consumers will adopt visible characteristics or invisible characteristics to describe the value factors. The awareness is reflected as the ability to see the hidden fact from the obvious things [4]. The essence of consumer awareness is to understand the composition factors of customers' value. These factors are reflected in value improvement, value maintenance, and value destroy three aspects. When enterprises make a definition of consumers' value, it is necessary to find the factors improving consumers' value. These factors can break the routine or never appear in the market. For instance, compared to the traditional stores, the convenience of on-line shopping greatly improves consumers' value. The reason for the vigorous development of apple iPod is that the company has a profound awareness of simple and convenient demand of consumers when they are enjoying the music [5]. The value maintenance factor is the core characteristic and attributes needed for enterprises to satisfy the consumers. It is similar to "health care factor" that enterprises must regularly check these factors, so as to ensure that they can play the role of supporting. In a word, enterprises are supposed to make efforts to dig out the value improvement factors, protect the value maintenance factors, and eliminate the value destroy factors when we make a definition of consumers' value. Market division plays an essential role in the value definition because through division, enterprises can find the most suitable target market and formulate the consumer strategy with better cost benefits. The new consumer market is highly fine divided, which mainly because the life is complex and a consumer can have several roles and appear in various forms.

Secondly, it supposed to make value creation with innovative thinking. Only value definition but no value creation, the enterprise marketing still cannot be realized. The essence of value creation is to provide consumers with value scheme that they expect to purchase, and of course, the scheme must be mutually beneficial. In the value creation, enterprises are supposed to carefully consider new product development, brand management, market positioning, product price and so on factors because they all play an important role in the value creation process. Innovation is the basic idea to guide the enterprise value creation [6]. The new product development itself is innovation, but it does not mean that providing more technological content for new products will bring value-added innovation. The key point is that this kind of innovation must bring customers with new value or value improvement, such as increasing economy, choice, experience, convenience, rapidity, sense of dignity and so on. The meaning of brand for consumers lies in the experience, and the experience brings consumers with rational, emotional, social and cultural comprehensive benefits.

Finally, it requires to demise the value with flexibility. Only when the value creation is demised can it really complete the value realization. The role of media and channels in the value demission, the media spreads the value scheme for consumers and the channels mainly complete the transaction of value scheme. New consumers faced an open world, and they have more opportunities to acquire more choices, greater convenience, and lower price. For this, in allusion to new consumers, enterprises must improve the stronger customer response ability through enhancing the enterprise flexibility in the value demission. And thus, it can better provide customers with service and personalized value scheme, and achieve the low cost of enterprise operation. With the continuous development of information and technology, the media is closely related to channels and even exchange, which provides technological conditions for enterprises' flexible value demission. For new consumers, enterprises need to give full play of media, especially interactive media (such as direct 
mail, telephone hotline, e-mail, personal digital assistant, mobile phones and so on), so as to achieve more and continuous exchange between enterprises and consumers. In various interactive media and non-interactive media, enterprises marketing staffs need to choose the most efficient and effective media combination.

\section{Current situation of China's consumer financial market}

Chinese consumption finance is still in the initial stage, and consumption credit has a small proportion in the bank credit business. By the end of 2012, the balance of Chinese consumption finance is 104357 billion yuan in total. It occupies about $15 \%$ of the total amount of financial institute credit in that year. However, Chinese consumption finance market has the advantages of rapid growth speed and wide popularization. Chinese consumption credit scale increases with the speed of $24 \%$ annually in the next five years, and reaches about 21 trillion yuan in 2015 [7]. Chinese consumption market has great growth potential and development space. The credit consumption loan balance and growth rate in China is shown in figure 1.

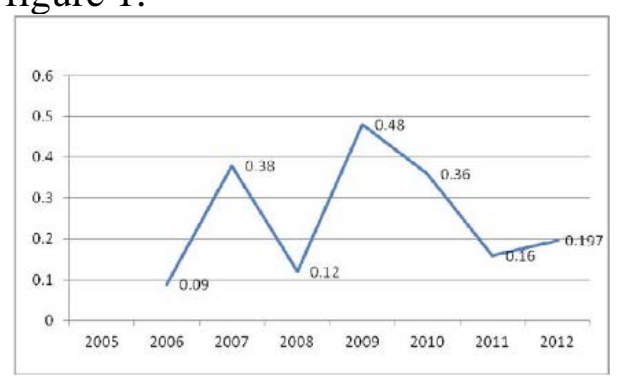

Fig 1. Credit consumption loan balance and growth rate in China from 2005 to 2012

By the end of the first quarter of 2013, the consumption credit balance of Industrial and Commercial Bank of China and so on five commercial banks is 65537 billion yuan, increased 8998 billion yuan compared to the same period of the last year, having an increase of $15.9 \%$, accounting for more than $95 \%$ of Chinese consumption finance business. The state-owned commercial bank occupies an absolute advantage at present depending on its historical advantages and brand effect. Taking China Construction Bank as an example, the personal consumption credits operated mainly include personal housing mortgage loan, commercial housing loans for individual transactions and so on businesses. As a result, a relatively complete credit product system with a wide coverage is formed.

Consumption finance company refers to non-bank financial institute established in Chinese territory, not absorbing public deposit, which provides small amount of credit as the consumption purpose for domestic resident individuals. In 2009, China Banking Regulatory Commission (CBRC) published "Consumer finance companies pilot management method" and uncovered the prelude of Chinese consumption finance company development. At present, the pilot of consumption finance company has been conducted in Beijing, Shanghai, Chengdu, and Tianjin four cities.Consumption finance companies, different from Commercial Bank, pay more attention to middle-income class, and focus on the personal consumption credit for general use. They are the supplement for each other in the consumption credit field and Commercial Bank, and from a product system with personal durable consumer goods credit and general use consumption credit as major parts. That is to say, distributors give out the credit used for purchasing the agreed household electric appliances, electric products and so on durable consumption products (do not include houses and cars) or credit used for personal or family tourism, wedding celebration, education, decoration and so on consumption items directly given out for borrower. However, interfered by high interest rate caused by insufficient capital sources and high risk premium, in a short term, consumption finance companies are limited in promoting the consumption and pushing domestic demand. By the end of October, 2012, the credit balance of four companies is 37.09 billion yuan in total, among which the balance of the largest Beijing Bank consumption finance company is 19 billion yuan in total, accounting for a small proportion in the consumption credit. 


\section{Problems in the construction of financial market system}

Through the above analysis, we can see that the current consumption finance market in China is still at the initial stage, and its role is not yet clear. On the surface, it can be attributed to the backwardness and imperfection of China's consumer finance market. In essence, it is mainly a mismatch between the current consumption financial market system and the new consumer concept. This mismatch can be summer up to three aspects.

\subsection{Mismatch between single consumer financial market institutions and consumer financial needs}

The institutional system of providing consumer finance is relatively simple, and it is difficult to meet the demand of consumer finance needs. The commercial banks occupy the dominant position in the consumer financial market, in which large and medium-sized banks are the main ones. The situation makes it difficult to accept their consumer financial services in the construction of financial market system. On the one hand, these large and medium-sized financial institutions have fewer branches, and the cost of dealing with all business transactions is relatively high. On the other hand, the relatively strict risk credit system of large and medium-sized financial institutions also makes the business of their county agencies relatively limited. Consumer finance companies and other consumer finance platforms are mainly concentrated in large and medium-sized cities. In addition, the overall financing scale is small, the social recognition is relatively low, and the support is limited. First of all, the category of consumer credit business is single and disjointed with the demand. The main service object of the traditional consumer finance institution is the customs with large demand of the money, such as the housing loan, the car loan and so on. By the end of the first quarter of 2013, the balance of individual housing loans of five state-owned commercial banks in China was 58310 billion yuan, and the balance of automobile consumption loans was 47.2 billion yuan. The balance of personal housing loans and car consumer loans accounted for $89.7 \%$ of the balance of the consumer loan. But for the new consumers, their consumption and financial demand is relatively scattered, and the amount is not high enough. In the supply of existing consumer financial products, its consumption demand is rarely met. Secondly, the existing consumer financial products are designed for common residents, while the construction of financial market as a new trend of development, many new consumer financial needs emerged in the development, such as decoration, wedding, tourism, education and training and other emerging consumer demands, which are out of the existing consumer financial products.

\subsection{Environment for the development of consumer finance remained to be improved}

The biggest risk of consumer finance is credit risk. The consumer financial market is directly faced with personal credit. Compared with legal persons, the privacy of personal information is even higher. It is difficult for financial institutions to verify the authenticity of information provided by borrowers, especially for those quantitative soft information. At present, our country has not established a perfect personal credit system. Personal credit records are scattered in People's Bank, telecommunications, taxation, public security, transportation, electricity providers and other departments. They cannot get timely communication or effective integration, and the procedures are complicated and the channels of sharing are not smooth [8]. This objectively causes the problems of cumbersome credit procedures and high cost of credit evaluation, which restricts the development of consumer finance. In order to avoid more adverse selection and moral hazard, higher risk compensation can only be added to increase interest rate, and the increase of interest rate further expands the credit risk. The lack of personal credit system leads to the lack of effective control of credit risk. It is a difficult problem to be faced to solve the demand of consumer finance in the construction of financial market system. This is particularly evident in the small and medium-sized cities, especially in the rural areas, and it makes the main supply body of the consumption finance prohibitive, resulting in insufficient supply. 


\section{Countermeasures and suggestions}

Through the above analysis, we can see that the new consumer concept has brought many opportunities for the vigorous development of consumer finance, and the further development of consumer finance will also effectively enhance the effectiveness, and put the essence and connotation of new consumer concept in practice. But from the current situation of China's consumer finance market, on the whole, it is still in the ascendant stage, and the consumption finance demand is not matched with new consumer concept. Therefore, it is very necessary and very important to speed up the construction of an effective consumer financial market system. Further, it is also the key to change the way of China's economic growth and expand domestic demand [9].

We should actively accelerate the construction of a multi-level consumer financial market supply system. We should encourage all kinds of consumer finance providers to actively engage in the important field of consumer finance demand. On the one hand, it is necessary to encourage the banking financial institutions so that the financial institutions can be more contacted and selected. On the other hand, it requires to lower the threshold for the establishment of consumer finance companies, introduce private capital to participate in the construction of consumer finance, achieve diversified participants, introduce competition mechanism, and achieve flexible interest rate [10]. At the same time, we must seize the opportune time to actively integrate into the consumer finance in the current e-commerce platform and other large business enterprises, actively guide and moderately tilt the policy, and encourage them to actively serve the consumption finance needs in the new era.

We are also supposed to increase product and business innovation to effectively meet the demand of consumer finance. Financial institutions should adapt to the requirements of the implementation of the strategy of finance, identify market orientation, accelerate the innovation of consumer credit varieties, and adapt to the needs of consumption and financing system reform. We should establish a product system based on individual housing loans, including automobile loans, credit card loans, durable consumer goods loans, decoration loans, educational loans, tourist loans, wedding loans and other products, and promote agricultural machinery consumption loans [11]. It also needs to enrich the product level, so as to meet the needs of the diversified consumption of residents. In business, we should cultivate consumer credit consciousness, popularize the consumer credit culture, guide the moderate advance consumption of consumers with stable income, and appropriately carry out unsecured micro credit business. Based on the full credit, we should moderately simplify business formalities to be fast and convenient. Through the cooperation with the e-commerce platform and the large business, we integrate financial services into the consumption process, and improve the matching and adaptability of consumer financial services.

\section{Conclusion}

China's current consumer credit legal system is not yet sound, and there is not a systematic credit law to support the development of China's consumer finance. Therefore, our country must accelerate the formulation of relevant laws to protect the creditor's rights of the consumer financial institutions with specific measures. At the same time, we should speed up the construction of the personal credit system. The establishment of the credit system is the basis and premise of the development of the consumer finance business. We should take the central bank led national personal credit system construction as the core, and strengthen the banking, public security, medical security, e-commerce and other types of credit information departments communication and coordination. In addition, it is necessary to integrate information resources of different types, accelerate the establishment of credit sorting, collection and sharing mechanism, grasp accurate statistics data, and perfect the personal credit evaluation system. 


\section{References}

[1] Francine Gresnigt, Erik Kole, \& Philip Hans Franses. (2015). Interpreting financial market crashes as earthquakes: a new early warning system for medium term crashes. Journal of Banking \& Finance, 56, 123-139.

[2] Lengnick, M., \& Wohltmann, H. W. (2016). Optimal monetary policy in a new keynesian model with animal spirits and financial markets. Journal of Economic Dynamics \& Control, 64, 148-165.

[3] Sayım, F. (2015). The participation banking as a distinctive method and the its growing in the turkish finance market-period: 2007-2013. Emaj Emerging Markets Journal, 5(1).

[4] V. Argiddi, R., S. Apte, S., \& S. Adam, V. (2015). The implication of tweet's distribution by quantizing stock values for inference in the indian financial market: a sentiment analysis approach. International Journal of Computer Applications, 109(8), 12-17.

[5] Ma, Q. J. (2016). China's financial regulatory system adjustment in the new period — - on the perspective of reassortment and coordination for administrative supervision of securities market. Journal of Political Science \& Law.

[6] Immonen, E. (2017). Simple agent-based dynamical system models for efficient financial markets: theory and examples. Journal of Mathematical Economics, 69, 38-53.

[7] Somboon, S., Somboon, S., \& Somboon, S. (2015). Credit scoring system for managing risk in agricultural loan portfolio of the thai rural financial market. Applied Economics Journal, 22.

[8] Ding, Y., \& Cao, J. (2015). Bifurcation analysis and chaos switchover phenomenon in a nonlinear financial system with delay feedback. International Journal of Bifurcation \& Chaos, 25(12), 2671-2691.

[9] Wang, J., Pan, H., Wang, Y., \& Niu, H. (2015). Complex system analysis on voter stochastic system and jump time effective neural network of stock market. International Journal of Computational Intelligence Systems, 8(4), 787-795.

[10]Calluzzo, P., \& Dong, G. N. (2015). Has the financial system become safer after the crisis? the changing nature of financial institution risk $\hat{\jmath}$. Journal of Banking \& Finance, 53, 233-248.

[11]Wanke, P., Azad, M. A. K., \& Barros, C. P. (2016). Financial distress and the malaysian dual baking system: a dynamic slacks approach. Journal of Banking \& Finance, 66, 1-18. 